\title{
Local and landscape influences on the habitat occupancy of the endangered maned sloth Bradypus torquatus within fragmented landscapes
}

\author{
Paloma Marques Santos ${ }^{\mathrm{a}, *}$, Adriano Garcia Chiarello ${ }^{\mathrm{b}}$, Milton Cezar Ribeiro ${ }^{\mathrm{c}}$, \\ John Wesley Ribeiro ${ }^{c}$, Adriano Pereira Paglia ${ }^{a}$ \\ a Laboratório de Ecologia e Conservação, Departamento de Biologia Geral, Instituto de Ciências Biológicas, Universidade Federal de Minas Gerais, Av \\ Presidente Antônio Carlos, 6627, Belo Horizonte 31270-901, MG, Brazil \\ ${ }^{\mathrm{b}}$ Departamento de Biologia, Faculdade de Filosofia, Ciências e Letras de Ribeirão Preto, Universidade de São Paulo, Av. Bandeirantes, 3900 , Ribeirão Preto \\ 14040-901, SP, Brazil \\ c Laboratório de Ecologia Espacial e Conservação (LEEC), Departamento de Ecologia, Universidade Estadual Paulista, Av. 24 A,1515, Rio Claro 13506-900, \\ SP, Brazil
}

\section{A R T I C L E I N F O}

\section{Article history:}

Received 30 October 2015

Accepted 10 June 2016

Handled by Francesco Ferretti

Available online 11 June 2016

\section{Keywords:}

Xenarthra

Pilosa

Atlantic forest

Fragmentation

\begin{abstract}
A B S T R A C T
The transformation of natural landscapes in extensive anthropogenic areas has significantly affected ecological processes, and studies that evaluate such changes are essential for the definition of conservation strategies. In this study, we sought to identify the variables influencing the occupancy of Atlantic forest fragments by the endemic and endangered maned sloth. We selected 33 sampling stations, distributed at least $500 \mathrm{~m}$ apart throughout the municipality of Santa Maria de Jetibá-ES, Brazil. We sampled each station five times to verify the presence or absence of the species and to collect local variables. Using GIS tools, we defined a buffer of $200 \mathrm{~m}$ around each fragment and calculated the landscape metrics. After analysis of collinearity, we selected six variables - three local variables, two at patch level and one at landscape level - to assess their effect on the occupancy and detection probabilities. We selected models using AICc and calculated the weight of evidence and ratio of the models as well as the cumulative weight of each predictor variable. We detected the sloth in $48 \%$ of the stations. Its occupation was positively correlated to two variables on the local scale: Important Feeding Trees and Canopy height. Our results show that the maned sloth respond to fine local scale variables, but not to landscape structure. This is probably associated with the relatively high proportion of forest cover in the study area, but it also indicates the maned sloth flexibility to occupy fragmented landscape. Based on our results, we reinforce the unquestionable importance of local variables for species occupancy within fragmented landscapes, such as those related with the forest structure, and it is particularly important for strictly arboreal species.
\end{abstract}

(c) 2016 Deutsche Gesellschaft für Säugetierkunde. Published by Elsevier GmbH. All rights reserved.

\section{Introduction}

Over the last two decades, studies on the effects of habitat loss and fragmentation have gained momentum in response to the intense transformation of natural landscapes into enormous agricultural areas, roads and urban agglomerations (Andrén, 1994; Gascon et al., 1999; Laurance and Peres, 2006). The current config-

\footnotetext{
* Corresponding author at: Departamento de Biologia Geral, sala 257, ICB/UFMG Av. Presidente Antônio Carlos, 6627, Pampulha Belo Horizonte, 31270-901, MG, Brazil.

E-mail addresses: paloma.marquessa@yahoo.com.br, paloomitta@gmail.com (P.M. Santos).
}

uration of most natural environments involves patches of various sizes and shapes within a heterogeneous anthropogenic matrix (Ricketts, 2001; Mayaux et al., 2005; Laurance, 2008; Ribeiro et al., 2009). This new conformation results in non-habitats for a variety of species and can disrupt several ecological and demographic processes (Ricketts, 2001; Laurance and Vasconcelos, 2009; Pütz et al., 2011). For instance, small and isolated fragments may not constitute good habitat for the many species that are negatively affected mainly by the reduced habitat availability and the edge effect (Araújo et al., 2015; Silva et al., 2015). However, small patches may represent available habitats for those species with small home range (Arroyo-Rodríguez and Dias, 2010). The same occurs for those species able to disperse through the anthropogenic matrix, allowing the minimum flow that guarantees the 
maintenance of populations (Ries and Debinski, 2001; Rodríguez et al., 2001; Castellón and Sieving, 2006). Such evidence shows the importance of studies that involve landscape configuration and dynamics (Bowers and Matter, 1997; Ricketts, 2001; Castellón and Sieving, 2006). Indeed, each group of species has different characteristics (e.g. dispersal capacity) and different ecological demands (e.g. habitat requirements) and, therefore, responds in distinct ways to landscape changes (Laurance, 2005). Therefore, patch and landscape characteristics serve as important environmental filters for the persistence of different groups of species (Gascon et al., 1999).

Other important selective filters relate to habitat features. In forest environments, factors such as canopy height, crown openness, floristic composition and forest stratification may influence the presence, richness and diversity of species in a region (August, 1983; Gentile and Fernandez, 1999; Grelle, 2003). In some cases, such variables are crucial to determine the occupancy of a particular group of species within a habitat patch (Gouveia et al., 2014).

The maned sloth, Bradypus torquatus (Pilosa: Bradypodidae), is endemic to the Atlantic Forest hostspot (Chiarello and Moraes-Barros, 2014), inhabiting almost exclusively the dense ombrophilous (evergreen) forests that occur in the lowland and lower montane areas in the eastern and northeastern sectors of this biome (Hirsch and Chiarello, 2012). Five centuries of human impacts have deeply affected the Atlantic Forest, with its extent reduced today to less than $12 \%$ of its original coverage and remaining fragments being mostly small, isolated and heavily subjected to edge effects (Ribeiro et al., 2009). The species is classified as Vulnerable in the IUCN Red List (Chiarello and Moraes-Barros, 2014) due primarily to habitat destruction and forest fragmentation, as well as the species' relatively poor dispersal capacity through non-forest areas (Chiarello et al., 2004; Hirsch and Chiarello, 2012). Considering that the presence of a species in a given forest fragment is related to a combination of factors acting at different scales, our goal was to evaluate the relative effect of local, patch and landscape variables on the occurrence of the maned sloth. Assuming that $B$. torquatus is sensitive to environmental filters, we expected that habitat features such as canopy height, canopy connection, and presence of important feeding trees would all positively influence the occupancy. We further expected that patch and landscape attributes such as the increase of the fragment size, the forest percentage, the matrix permeability and the average distance from the edge, would all positively influence the occupancy probability in sampled forest fragments.

\section{Material and methods}

\section{Study area}

The study was conducted in forest fragments in a mountainous region of Atlantic Forest hotspot, in the municipality of Santa Maria do Jetibá (20 $01^{\prime} 35^{\prime \prime}$ S; $40^{\circ} 44^{\prime} 27^{\prime \prime}$ W; Fig. 1), located in the central-south of Espírito Santo State, Brazil. The elevation in the municipality ranges from 600 to $1200 \mathrm{~m}$, and the relief slope ranges from $0^{\circ}$ and $70^{\circ}$ (Mendes, 2006). It has an annual rainfall of $1290 \mathrm{~mm}$, with rains concentrated in the summer (October-March); the average temperature is $20.6^{\circ} \mathrm{C}$ (annual range: $10-28^{\circ} \mathrm{C}$; Climate-data, 2015). The predominant forest formation is classified as dense evergreen forest, with trees that are 20-30 m tall and green year-round (Santos et al., 2012). The predominant landscape (about $36.0 \%$ ) of the study area is composed by secondary and old-growth forests, though when early-stage forests are also considered, the forested proportion reaches $46 \%$. The forest fragments are immersed in a heterogeneous anthropogenic matrix formed by eucalyptus (9.1\%), pastures and abandoned pastures (13.8\%), coffee cultivation (5.4\%) and other crops (21.5\%), rocky outcrops (1.7\%), water bodies $(0.5 \%)$ and urban area $(1.7 \%)$ (Centoducatte, 2011).

\section{Sampling design}

In total, we sampled 28 forest fragments (Fig. 1). First we selected 10 random fragments using ArcGIS 10.2 and chose the rest on or near places where field projects on other arboreal species had already been established (e.g. Projeto Muriqui-ES), facilitating our access through the prior authorization of the owners of the fragments. The chosen fragments differed in size, ranging from 0.5 ha to 947.7 ha (average 169.8 ha). We installed 33 sampling stations. We consider as station a sampling position within any forest patch, and depending on patch size, more than one station was sampled. One sampling station was installed in 24 of the fragments, two in three of the fragments and three in one fragment (Fig. 1). To minimized spatial autocorrelation (Fortin and Dale, 2005), the stations were located at least $500 \mathrm{~m}$ apart. This distance allowed for several home ranges (typically, home range size is $<10 \mathrm{ha}$ ) to exist between adjacent sampling units, and was much larger than the average distance traveled by sloths (Chiarello, 1998a). In the center of each station, we established two perpendicular trails, $200 \mathrm{~m}$ long and $1 \mathrm{~m}$ wide, forming a cross and resulting in an effectively sampled area of 1.32 ha per station (see Supplementary Fig. S1 in the online version at DOI: 10.1016/j.mambio.2016.06.003). On five separate survey occasions between April and August of 2014, we walked the trails for $1-2 \mathrm{~h}$ during the daytime ( $07 \mathrm{~h}$ and $17 \mathrm{~h}$ ), when maned sloths are more active (Chiarello, 1998a; Giné et al., 2015). We took notes about the presence (when the species was detected) and absence (when the species was not detected) of the species, and used this as our response variables in the models.

\section{Local environmental variables}

Seven habitat variables were measured in each sampling station, and for this, we considered the assessment of the species' potential habitat requirements and based on other studies involving arboreal mammals (August, 1983; Chiarello, 1998b; Kajin and Grelle, 2012). We measured the habitat variables in the center of the sampling station and at four other points established along the middle of each trail, totaling five measurement points for each variable per sampling station. In a 5-m radius around each of the five points, we visually estimated the presence or absence of arboreal (ArS-woody plants $>1.30 \mathrm{~m}$ ), shrubby (SrS-woody plants $<1.30 \mathrm{~m}$ ) and herbaceous (HbS-non-woody vegetation $<1 \mathrm{~m}$ ) strata (Richards, 1996; Olivo et al., 2006), bromeliads in trees (Brom) and vines (Vin); we did not define a minimum size for the last two measures. Following previous studies conducted in the same region (Chiarello, 1998b; Dias, 2008), we also measured the occurrence of at least one arboreal species that is known to be locally important in the diet and resting of B. torquatus-Cecropia spp., Ficus spp., Micropholis venulosa, Cupania furfuraceae (Important Feeding Trees-IFT). For all of these measures (Ars, SrS, HbS, Brom, Vin and IFT), the final value per sampling station was the proportion of points with presence of each variable. By the sum of the variances proportion of the measures Ars, SrS, HbS, Brom, Vin, we calculated the Habitat Complexity Index (HCI) adapted from August (1983) and Gentile and Fernandez (1999). This HCI is a proxy for the complexity of the habitat vertical variation. We used a rangefinder to measure Canopy Height $(\mathrm{CH})$ at the five points of each sampling station, measuring the height of the largest tree at that point. The final value for this variable is the average of five measurements. 


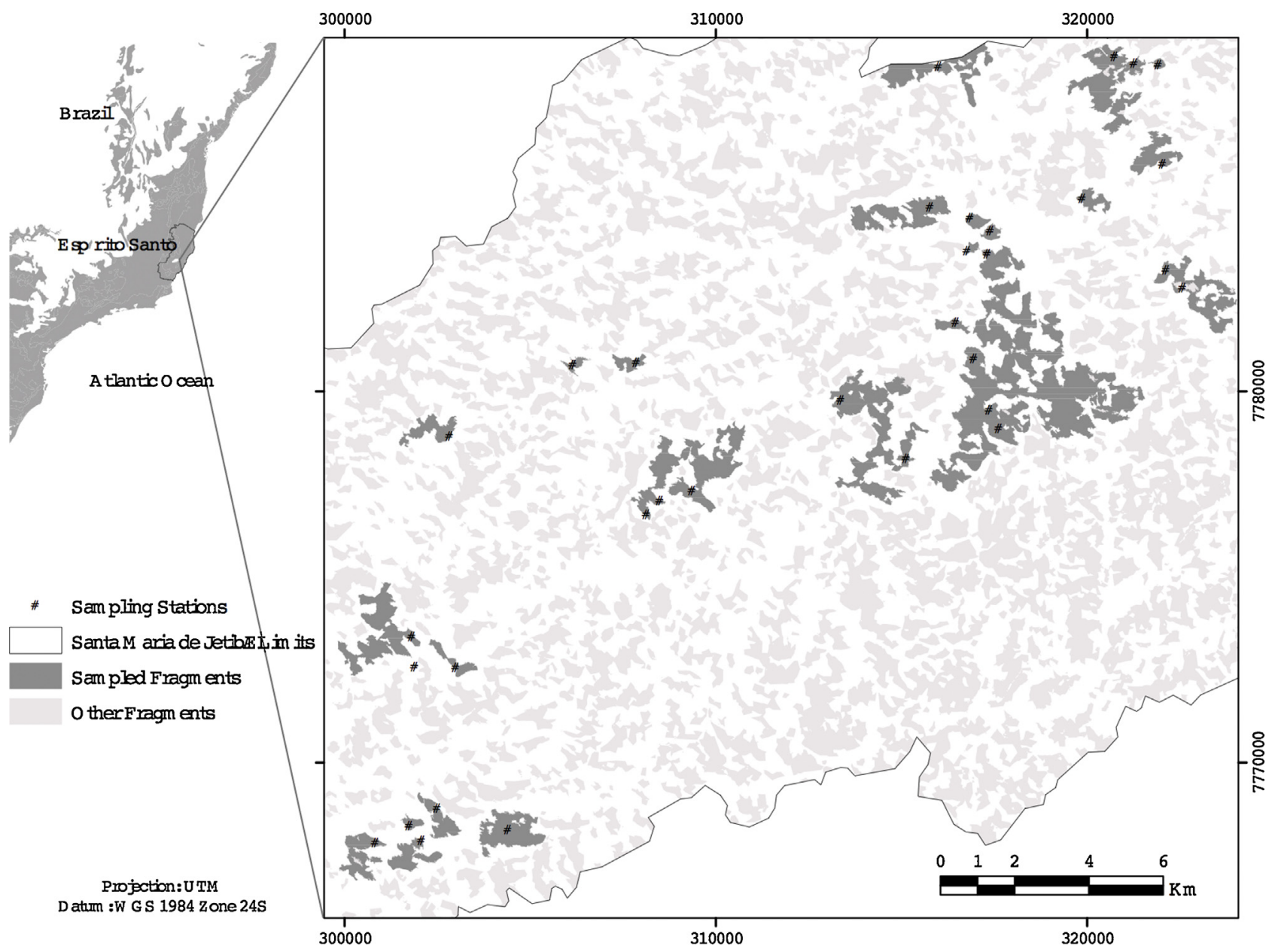

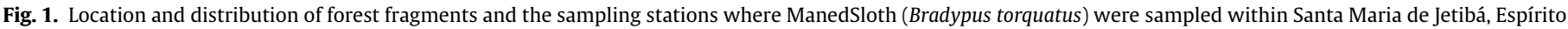
Santo, Brazil.

\section{Landscape structure variables}

We conducted the analyses of landscape variables using a land use map of the region for the year 2011, which was shared by the Projeto Muriqui do Espírito Santo. The analyses were performed in the programs ArcGIS 10.2 (ESRI, 2013) and GRASS GIS 6.4.3 (Neteler and Mitasova, 2013); we processed the data in the program R Studio 3.1.1 (R Development Core Team, 2010).

We made a 200-m buffer around the sampled fragments for all analyses. Inside the buffer, we quantified the percentage of forests (PF). To estimate the Functional Isolation (FI), we used the "Empty Space Function" approach (Baddeley and Turner, 2005; Ribeiro et al., 2009; Bueno et al., 2013), which measures the average isolation of a random pixel in relation to the nearest forest area. To accomplish this, we randomized 10,000 points throughout the landscape and measured the distance of the fragment to those points located within the buffers, but out of other forest fragments. The resulting average distance values represented the average functional isolation (Fig. 2A).

Maps of the Matrix Influence (MI) address the influence of different land use classes on the species distribution or occurrence (see a similar approach for primates in Silva et al., 2015). For this, we prepared and analyzed the MI maps through two strategies: (a) Matrix Influence based on the Access to Resources (MIAR) and (b) Matrix Influence based on the Mobility (MIM) of the species; both strategies considered the weights for each class of land use and occupation. A value in the range of 1-100 was assigned to each class of land use, where 1 indicates a low resistance to mobility or high resource availability (most positive influence) and 100 indicates a high resistance to movement or low resource availability (most negative influence). To reach these values, we interviewed six experts on Bradypus ssp., using Delphi method (Estes and Kuespert, 1976; Mukherjee et al., 2015). We extracted the averages for both resources (MIAR) and mobility (MIM) provided by the experts and input them into the raster map of the region. The result was a weighted average of the influence of the matrix on a given sampling station, within the buffer.

We also calculated the randomized points' (see above) average distance from the forest edge (ADE). ADE indicates the average distance between the edge and some point within the fragment. In landscapes with large fragments, this average distance is higher because the central point of the forest patch is farther from the border. On the other hand, smaller fragments have shorter average distances when compared to large ones. In these analyses, we used only those points located within the fragment, using quantiles to divide the points into groups according to their distance from the edge. Only the values of the second quantile (Q2/3), i.e, those representing $50 \%$ of the points around the median value, were used (Fig. 2B). In addition to the ADE, we also used the fragment area (Area) as a patch level variable.

\section{Selection of variables}

Initially, we generated nine local, patch and landscape variables per sampling station. We reduced the number of variables to six after an analysis of collinearity using a correlation matrix, elim- 
A)

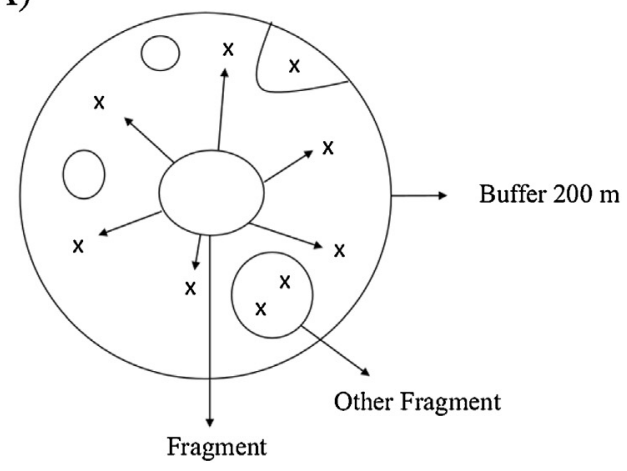

B)

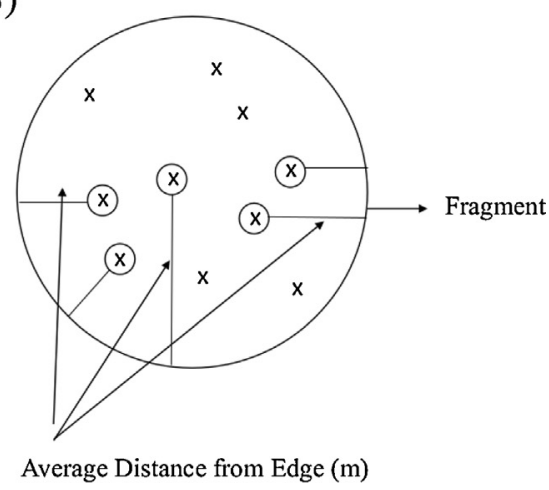

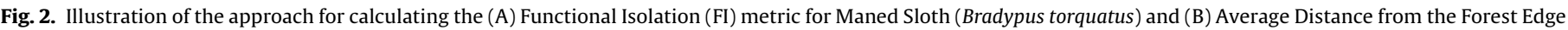
(ADE) within fragmented landscapes of Santa Maria de Jetibá, Espírito Santo, Brazil. The "x" represents the randomized points.

Table 1

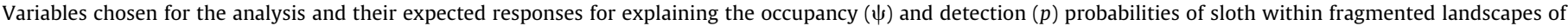
Santa Maria de Jetibá, Espirito Santo State, Atlantic Forest, Brazil.

\begin{tabular}{|c|c|c|}
\hline Local Variables & Parameter & Expected response \\
\hline Canopy Height $(\mathrm{CH})$ & $\psi / p$ & $\begin{array}{l}\text { The greater the height average, the lower the detection probability/higher } \\
\text { the occupancy probability. }\end{array}$ \\
\hline Important Feeding Trees (IFT) & $\psi / p$ & $\begin{array}{l}\text { The larger the proportion of these specific species present at the sampling } \\
\text { station, the higher the occupancy/detection. }\end{array}$ \\
\hline Habitat Complexity Index (HCI) & $\psi / p$ & $\begin{array}{l}\text { The greater the index, the lower the detection probability/higher the } \\
\text { occupancy probability. }\end{array}$ \\
\hline Patch scale Variables & Parameter & Expected response \\
\hline Area (Area) & $\Psi$ & The greater the area, the greater the occupancy probability. \\
\hline Average Distance from the Edge (ADE) & $\psi / p$ & $\begin{array}{l}\text { The greater the distance, the lower the detection probability/higher the } \\
\text { occupancy probability. }\end{array}$ \\
\hline Landscape Variable & Parameter & Expected response \\
\hline Proportion of Forested Area (PF) & $\Psi$ & The greater the proportion, the greater the occupancy probability. \\
\hline
\end{tabular}

inating all the variables with a high Personís correlation, $r>0.7$ (Zuur et al., 2009). After that, we used the selected variables (three local variables, two at patch level and one at landscape level) in our models (Table 1). We evaluated the influence of all variables on occupancy of the fragments by sloths and the influence of four of these variables on the detection probability (Table 1 )

\section{Occupancy, detection and model selection}

Using the program Presence (Hines, 2006), we assessed goodness of fit (GOF) for our most parameterized model structure (composed of all covariates for $\Psi$ and $p$ ), calculating the bootstrap with 10,000 randomizations and using the c-hat value of this global model. The c-hat measures the amount of extra-binomial variation or over-dispersion in the data, which can result from biological reasons (e.g. poor selection of covariates) or from statistical reasons (e.g. lack of independence among sampling units or other assumptions violations). The modeling of occupancy follows three main assumptions: (1) the system is demographically closed; (2) sites are independent; and (3) species are not falsely detected. A general rule of thumb is that $\mathrm{c}$-hat values $\leq 1.10$ indicate a model of good fit (Burnham and Anderson, 2002; Cooch and White, 2014).

Using the program Mark (White and Burnham, 1999) and a single-season model on five separated occasions, we calculated the occupancy $(\psi)$ and detection $(p)$ probabilities through a two-step approach (Mackenzie et al., 2006): (1) the probability of detection $(p)$ was estimated, setting all of the occupancy variables in the psi $(\psi)[\psi($ Global $)]$ and selecting the most important detection variables [ $p$ (variable)]; (2) after fixing $p$, the occupancy $\operatorname{probability}(\psi)$ was estimated, exchanging and modeling the variables for this parameter. The occupancy and detection estimates (response vari- ables, based on the sightings) were calculated throughout logistic regressions (logit link function) of the predictor variables, i.e. the local, patch and landscape level variables. We established a maximum of two occupancy variables per model to avoid over parameterization.

We generated and analyzed a set of 24 candidate models to explain occupancy and a set of 11 candidate models to select the most plausible models for detection. The selection of the models was based on the second-order Akaike Information Criterion (AICc) (Burnham and Anderson, 2002; Mackenzie et al., 2006), selecting only those models with $\Delta \mathrm{AICc}<2$ (Mackenzie et al., 2006). In addition, we used the AICc weight (wAICc), which represents the weight of evidence in favor of a certain model being the best. We also used the evidence ratio, which indicates the weight of each model relative to the others (Burnham and Anderson, 2002). We also calculated the cumulative weight of evidence - the sum of the wAICc of each variable in all models in which it occurs - for both detection and occupancy, revealing the relative importance of each variable in explaining the data (Burnham and Anderson, 2002; Cooch and White, 2014).

\section{Results}

\section{Maned sloth and site characteristics}

We detected the maned sloth at 16 of the 33 sampling stations (48\%). More than half of the sites with detection of the species (10 patches; $62.50 \%$ ) were located in small fragments ( $<100 \mathrm{ha})$. Sampling stations presented a relatively high average canopy height $(20.9 \mathrm{~m})$, and the average proportion of Important Feeding Trees within each station was 62\% (Table 2). Among all the sampling 
Table 2

General characteristics of the sample units in Santa Maria de Jetibá, Espirito Santo, Atlantic forest, Brazil. Where: $\mathrm{CH}=$ Canopy Height; $\mathrm{HCI}=$ Habitat Complex Index; IFT = Important Feeding Trees; $\mathrm{ADE}=$ Average Distance from Edge; $\mathrm{PF}=$ Percentage of Forests; FI = Functional Isolation; MIAR = Matrix Influence based on the Access to Resources; MIM = Matrix Influence based on the Mobility.

\begin{tabular}{llcc}
\hline Variable Classification & Name & Mean & Standard Deviation \\
\hline Local Variables & CH (m) & 20.87 & 4.68 \\
& HCI & 14.95 & 7.19 \\
\multirow{3}{*}{ Patch Variables } & IFT (\%) & 62.0 & $33.0 \%$ \\
& Area (ha) & 160.79 & 269.73 \\
Landscape Variables & ADE (m) & 63.76 & 32.38 \\
& PF (\%) & 78.0 & 0.12 \\
& FI $^{\mathrm{a}}(\mathrm{m})$ & 72.42 & 34.74 \\
& MIAR $^{\mathrm{a}}$ & 25.47 & 2.51 \\
& MIM $^{\mathrm{a}}$ & 12.30 & 3.31 \\
\hline
\end{tabular}

a Variables not used in the occupancy models.

Table 3

Summary of model selection procedure to verify the variables that affect detection probability of occupancy of sloth within fragmented landscapes of Santa Maria de Jetibá, Espirito Santo State, Brazil. AICc =s-order AIC, wAICc = Model weight, $L=$ Model Likelihood and $K=$ number of parameters.

\begin{tabular}{|c|c|c|c|c|c|}
\hline Model & AICc & $\triangle \mathrm{AICc}$ & wAICc & $L$ & K \\
\hline$\psi($ Global $), p(\mathrm{CH})$ & 135.715 & 0 & 0.479 & 1 & 9 \\
\hline$\psi($ Global $), p($ IFT $)$ & 138.871 & 3.156 & 0.099 & 0.206 & 9 \\
\hline$\psi($ Global $), p(\mathrm{ADE})$ & 138.937 & 3.222 & 0.096 & 0.200 & 9 \\
\hline$\psi($ Global $), p(\mathrm{HCI})$ & 139.385 & 3.670 & 0.076 & 0.160 & 9 \\
\hline$\psi($ Global $), p(\mathrm{CH}, \mathrm{ADE})$ & 139.438 & 3.724 & 0.074 & 0.155 & 10 \\
\hline$\psi($ Global $), p(\mathrm{CH}, \mathrm{HCI})$ & 139.659 & 3.944 & 0.067 & 0.139 & 10 \\
\hline$\psi($ Global $), p(\mathrm{CH}, \mathrm{IFT})$ & 139.682 & 3.970 & 0.066 & 0.138 & 10 \\
\hline$\psi($ Global $), p(\mathrm{IFT}, \mathrm{ADE})$ & 142.532 & 6.817 & 0.016 & 0.033 & 10 \\
\hline$\psi($ Global $), p(\mathrm{HCI}, \mathrm{ADE})$ & 142.907 & 7.192 & 0.013 & 0.027 & 10 \\
\hline$\psi($ Global $), p($ IFT, HCI $)$ & 143.043 & 7.328 & 0.012 & 0.026 & 10 \\
\hline$\psi($ Global $), p()$. & 146.466 & 10.751 & 0.002 & 0.005 & 7 \\
\hline
\end{tabular}

points, only one forest patch was larger than 900 ha. The relatively small size of the fragments was also evident in the average distance from the core area to the edge: the sampled fragments exhibited an average distance of $64 \mathrm{~m}$ to non-forested areas and a functional isolation of only $72.4 \mathrm{~m}$ (Table 2). The average values of the Matrix Influence based on the Access to Resources (MIAR) and on Mobility (MIM) were 25 and 12, respectively, with low standard deviations, indicating high level of homogeneity between the sites. The percentage of forest on 200 -m radius buffers was high at $78 \%$ on average (Table 2 ).

\section{Occupancy and detection estimation}

The bootstrap goodness-of-fit test revealed no over-dispersion in the data (c-hat=0.80). Among the 11 candidate models, only the model with Canopy Height $(\mathrm{CH})$ were plausible to estimate the detection of maned sloth (Table 3 ). The higher the canopy height, the higher the detection (Fig. 3A). The cumulative wAICc of $\mathrm{CH}$ was $68.57 \%$.

Among the 24 models with occupancy, only one was considered as plausible $(\triangle A I C C \leq 2$; Table 4$)$. This model indicates a positive association between the proportion of Important Feeding Trees ( $\beta=6.06 \pm 3.58$; mean \pm standard error; Fig. $3 \mathrm{~B})$ and the average Canopy Height ( $\beta=0.66 \pm 0.53$; Fig. $3 C$ ) and the probability of occupancy, which had the value of $0.89 \pm 0.17$. This occupancy value was an average of each covariate included in the additive model. However, the precision of the estimated betas was poor, with the confidence intervals ranging from negative to positive. Nevertheless, the weight of evidence of the first model was three times higher than second (null model).
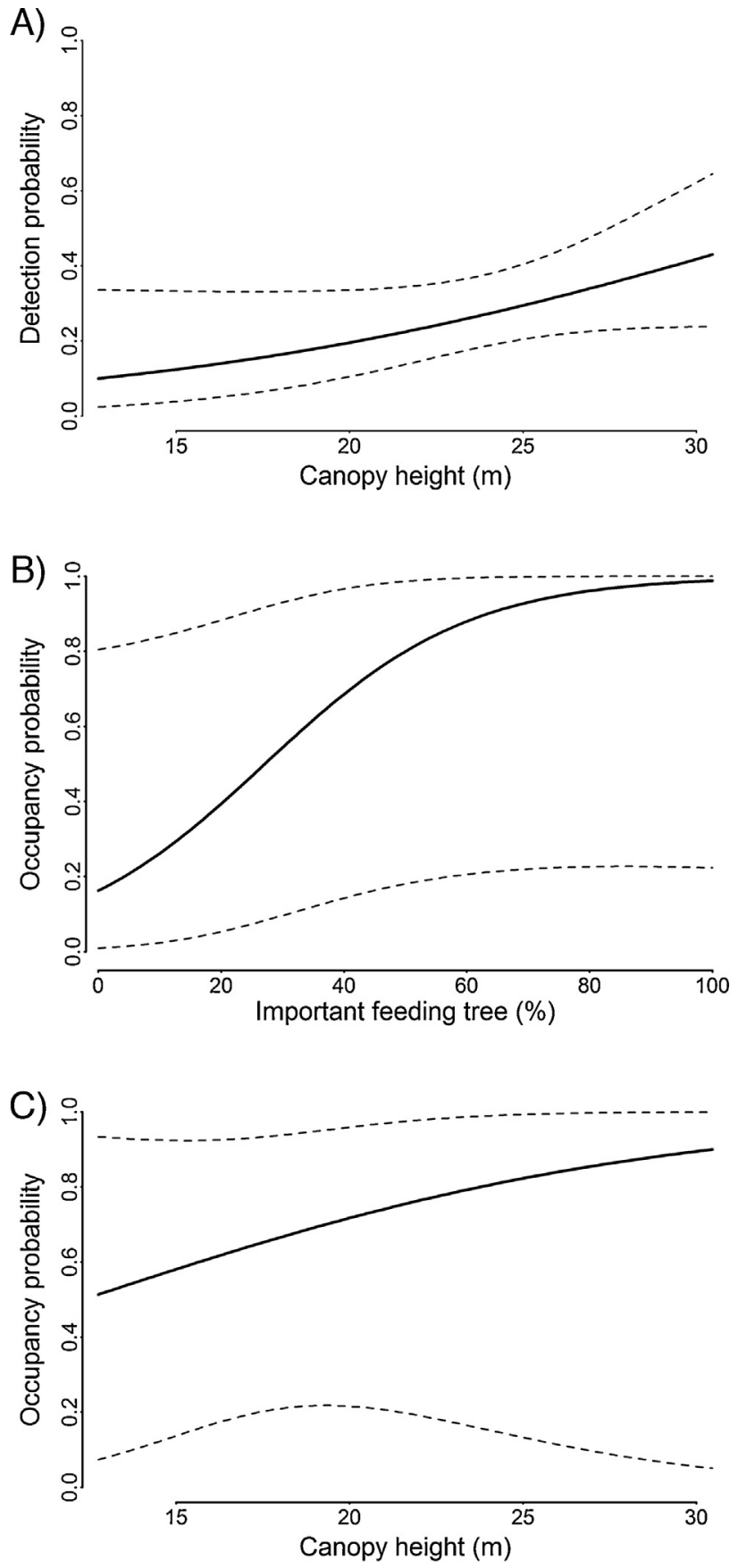

Fig. 3. Occupancy and detection probability and $95 \%$ confidence intervals of maned sloth (Bradypus torquatus) versus the two explanatory variables (A-Canopy Height for detection; B-Proportion of Important Feeding Trees and C-Canopy Height for occupancy). To construct these graphs, we used the single variable of the best-ranked model.

After analyse the cumulative wAICc of each variable, the variable Canopy Height stand as the most important local predictor of occupancy (cumulative wAICc $=0.490$ ), with strong support for the data, followed by Important Feeding Trees (0.475). In an overall perspective, models with patch-level and landscape variables had weak support: $\mathrm{ADE}=0.122$, Area $=0.106$ and $\mathrm{PF}=0.210$. The cumulative wAICc of HCI was 0.111. 
Table 4

Summary of model selection procedure to verify the variables that affect the occupancy probability of sloth within fragmented landscapes of Santa Maria de Jetibá, Espirito Santo State, Brazil. AICc = s-order AIC, wAICc = Model weight, $L=$ Model Likelihood $K=$ number of parameters.

\begin{tabular}{lllllr}
\hline Model & AICc & $\Delta$ AICc & wAICc & \multicolumn{1}{l}{$L$} & \multicolumn{1}{l}{$K$} \\
\hline$\psi($ IFT, CH $), p(\mathrm{CH})$ & 126.386 & 0 & 0.311 & 1.000 & 5 \\
$\psi(),. p(\mathrm{CH})$ & 128.620 & 2.234 & 0.102 & 0.327 & 3 \\
$\psi(\mathrm{IFT}), p(\mathrm{CH})$ & 129.542 & 3.156 & 0.064 & 0.206 & 4 \\
$\psi(\mathrm{CH}), p(\mathrm{CH})$ & 129.632 & 3.246 & 0.061 & 0.197 & 4 \\
$\psi(\mathrm{PF}), p(\mathrm{CH})$ & 129.663 & 3.277 & 0.061 & 0.194 & 4 \\
$\psi(\mathrm{CH}, \mathrm{PF}), p(\mathrm{CH})$ & 129.740 & 3.354 & 0.058 & 0.187 & 5 \\
$\psi(\mathrm{ADE}), p(\mathrm{CH})$ & 130.432 & 4.046 & 0.041 & 0.132 & 4 \\
$\psi($ IFT, PF), $p(\mathrm{CH})$ & 130.667 & 4.281 & 0.036 & 0.118 & 5 \\
$\psi($ Area $), p(\mathrm{CH})$ & 131.219 & 4.833 & 0.028 & 0.089 & 4 \\
$\psi(\mathrm{HCI}), p(\mathrm{CH})$ & 131.221 & 4.835 & 0.028 & 0.089 & 4 \\
$\psi(\mathrm{CH}, \mathrm{Area}), p(\mathrm{CH})$ & 131.412 & 5.026 & 0.025 & 0.081 & 5 \\
$\psi(\mathrm{IFT}, \mathrm{HCI}), p(\mathrm{CH})$ & 131.424 & 5.038 & 0.025 & 0.080 & 5 \\
$\psi(\mathrm{IFT}, \mathrm{ADE}), p(\mathrm{CH})$ & 131.639 & 5.253 & 0.022 & 0.072 & 5 \\
$\psi(\mathrm{ADE}, \mathrm{PF}), p(\mathrm{CH})$ & 131.693 & 5.307 & 0.022 & 0.070 & 5 \\
$\psi(\mathrm{PF}, \mathrm{HCI}), p(\mathrm{CH})$ & 132.085 & 5.700 & 0.018 & 0.058 & 5 \\
$\psi(\mathrm{CH}, \mathrm{HCI}), p(\mathrm{CH})$ & 132.092 & 5.705 & 0.018 & 0.058 & 5 \\
$\psi(\mathrm{CH}, \mathrm{ADE}), p(\mathrm{CH})$ & 132.292 & 5.906 & 0.016 & 0.052 & 5 \\
$\psi(\mathrm{IFT}, \mathrm{Area}), p(\mathrm{CH})$ & 132.303 & 5.917 & 0.016 & 0.052 & 5 \\
$\psi($ Area, PF), $p(\mathrm{CH})$ & 132.456 & 6.069 & 0.015 & 0.048 & 5 \\
$\psi($ Area, HCI $), p(\mathrm{CH})$ & 132.919 & 6.533 & 0.012 & 0.038 & 5 \\
$\psi(\mathrm{ADE}, \mathrm{Area}), p(\mathrm{CH})$ & 133.199 & 6.813 & 0.010 & 0.033 & 5 \\
$\psi(\mathrm{ADE}, \mathrm{HCI}), p(\mathrm{CH})$ & 133.223 & 6.837 & 0.010 & 0.033 & 5 \\
Null & 141.322 & 14.936 & 0.000 & 0.000 & 2 \\
Global & 148.629 & 22.243 & 0 & 0 & 12 \\
\hline
\end{tabular}

\section{Discussion}

Our results indicate that the maned sloth is more sensitive to habitat variables than to patch or landscape attributes, which may occur because of speciesí characteristics such as the strictly arboreal habit, long periods spent in the forest canopy, small home range and low mobility. Sloths frequently spend several days in the same tree, remaining at rest and feeding on leaves and shoots (Montgomery and Sunquist, 1975; Chiarello, 1998b; Cassano et al., 2011; Giné et al., 2015). Large trees generally have larger crowns, with lianas that serve as connectors between neighboring trees (Sanquetta et al., 2011). Thus, the presence of tall and connected canopy is the preferable habitat for the species, as it facilitates movement between trees and reduces the sloth's vulnerability to terrestrial predators (Cassano et al., 2011). This may explain the positive relationship between the detection probability and the canopy height, which was contrary to our expectations, based on previous field experience (the higher a sloth is in the canopy the harder it gets for a human observer to spot it from the ground). This surprising result indicates that, even though it is hard to detect sloths on taller canopies, these places are the best habitat for sloths, sustaining therefore many individuals (or higher frequency of visits), which in turn counterbalance the sighting difficulties imposed by the vegetation. Similarly, trees of dietary importance are relevant to the presence of the sloth in a specific location, as shown here and in other studies (Chiarello, 1998b; Cassano et al., 2011).

The large amount of forest in the region undoubtedly contributes positively to the occupation of the maned sloth in more than $80 \%$ of forest patches within the region, irrespectively from age, habitat quality and patch size. Although the large majority of fragments were small, they were not completely isolated, and on average, they were located $72.4 \mathrm{~m}$ from other forest fragment. The high percentage of forest inside the $200-\mathrm{m}$ radius and the low, almost constant influence of matrix also reflects this high connectivity between the forest patches. The fragments were so close to each other that the matrix offers little resistance and does not appear to be a barrier to the movement of the species. Santa Maria de Jetibá is composed of a moderately fragmented landscape with forest patches of varying size. Even so, it has a high percentage of forest cover: $37 \%$ - reaching $46 \%$ if young forests are included in the calculation - which is greater than the average forest amount found by Ribeiro et al. (2009) for the Atlantic Forest biome. Theoretical and empirical studies suggest that regions with less than $30 \%$ forest cover are influenced strongly by their landscape configuration (Andrén, 1994), with a consequent loss of species and decrease of ecological processes and gene flow as this percentage decreases (Metzger et al., 2009; Pütz et al., 2011). At 40\% forest cover, the patches are not entirely isolated, thus allowing dispersion (Andrén, 1994; Fahrig, 2003). In a recent study, Muylaert et al. (2016) studied bat richnessís response to habitat amount within Cerrado-Mata Atlantic transitional zones in Brazil and found that, above the 47\% of habitat amount threshold, bat richness was higher, when compared to the patterns found below this threshold. Martensen et al. (2012) observed a similar pattern, where understory birdsís richness was higher within landscapes with c.a. 50\% of forest cover within the Brazilian Atlantic Forest hotspot, and lower below 30\% of forest cover threshold.

Further, despite the risks of being attacked by domestic dogs and of death by motor vehicle (Vaughan et al., 2007; Peery and Pauli, 2014; Silva et al., 2014), recent studies indicate that sloths can use modified habitats, such as cabrucas (cocoa agroforests) and cocoa plantations, in search of their preferred trees (Vaughan et al., 2007; Cassano et al., 2011) or during dispersal events. In Santa Maria de Jetibá, B. torquatus, as well as the Brown Howler Monkey (Alouatta guariba), have been observed moving through coffee and eucalyptus plantations-systems that are often located next to forest patches and correspond to $14.5 \%$ of the land use. Selectively logged forests, agroforestry systems and even plantations such as coffee can therefore play an important role in biodiversity conservation. These landscape elements increase the permeability of the matrix (Moguel and Toledo, 1999; Jose, 2009) and can be used by several species of mammals to disperse among close fragments (Zollner and Lima, 2005; Prevedello and Vieira, 2010), especially if they are arranged in parallel lines (plantations rows-Prevedello and Vieira, 2010).

Besides the current study, there are some other evidences that the maned sloth can be present in diverse fragments of the region (Chiarello et al., 2004; S.L. Mendes, pers. comm), a consequence not only of the landscape features, but also of the ecology of the species. There is growing evidence suggesting that sloths in general are unconcerned with the size of a forest remnant; this may be due to their small home range ( 0.5 ha-10.8 ha; Chiarello, 2008), which, coupled with its varied diet, allows the species to occupy different forest types (Chiarello, 2008), including those located less than $100 \mathrm{~m}$ from edges. Sloths are considered to be generalists with respect to the large number of trees they use, though the individual's use of tree species may be more restricted (Chiarello, 2008). Individuals with close or overlapping home ranges feed on different sets of species, resulting in the consumption of a wide range of trees from different ecological vegetation groups - pioneer, intermediate secondary and late secondary - present both in the core areas of the patch as well as in the borders (Montgomery, 1978; Chiarello, 1998b; Cassano et al., 2011).

The persistence of an endangered species in a landscape composed mainly by small and medium-sized fragments underscores the need to reconsider the evaluation of conserving this type of forest patch (Bowers and Matter, 1997; Tscharntke et al., 2002). On his work on Central Europe, Tscharntke et al. (2002) emphasized that conservation plans aimed only at large fragments may not correspond to the reality of fragmented landscapes where land use are dominated by agricultural areas, urban areas, eucalyptus or pastures. Small forest patches immersed in a mosaic of altered environments can maintain high species richness in the region, given the great heterogeneity of habitats (Tscharntke et al., 2002), and can 
decrease the average isolation of the landscape (Ribeiro et al., 2009). This scenario applies to the Atlantic Forest, most of which (83\%) is composed of fragments smaller than 50 ha (Ribeiro et al., 2009). Thus, concentrating efforts to conserve areas composed of small patches can be a viable solution for the conservation of generalist species and species with a small living area. Those groups may be able to keep in landscapes with intermediate level of degradation, and continue performing their ecological functions. In such cases, the existence of the resources - as the local characteristics - may be more important than the degree of conservation per se, increasing the chance of diversity maintenance in a moderately fragmented landscape.

\section{Acknowledgements}

We would like to thanks: Sergio Lucena Mendes and the Projeto Muriqui/ES members for logistical support and for providing the satellite images; all the researchers that participated in the interview; the Brazilian science council, CNPq, for financial support; and the CAPES program for the Masters scholarship granted to Paloma Marques Santos at the Universidade Federal de Minas Gerais. We also thank the LEEC, UNESP - Rio Claro/SP, for the support during the analysis of images, and the Laboratório de Ecologia e Conservação de Mamíferos, USP - Ribeirão Preto/SP, for the support in the analysis of occupancy modeling. APP is funded by PRPq/UFMG, CNPq (process 306579/2015-4) and FAPEMIG. MCR is funded by São Paulo Research Foundation (FAPESP; grant 2013/50421-2) and CNPq research grant (process 312045/2013-1). AGC has a research grant from CNPq (305902/2014-8). Megan King, native English speaker from British Columbia (Canada), proofread the manuscript. We also are very thankful for the comments, suggestions and corrections made by the referees that surely helped us to improve the manuscript.

\section{References}

Andrén, H., 1994. Effects of habitat fragmentation on birds and mammals in landscapes with different proportions of suitable habitat: a review. Oikos 71, 355-366.

Araújo, L.S., Komonen, A., Lopes-Andrade, C., 2015. Influences of landscape structure on diversity of beetles associated with bracket fungi in Brazilian Atlantic forest. Biol. Conserv. 191, 659-666.

Arroyo-Rodríguez, V., Dias, P.A.D., 2010. Effects of habitat fragmentation and disturbance on howler monkeys: a review. Am. J. Primatol. 72, 1-16.

August, P.V., 1983. The role of habitat complexity and heterogeneity in structuring tropical mammal communities. Ecology 64, 1495-1507.

Baddeley, A., Turner, R., 2005. SPATSTAT: an R package for analyzing spatial point pattern. J. Stat. Software 12, 1-42.

Bowers, M.A., Matter, S.F., 1997. Landscape ecology of mammals: relationships between density and patch size. J. Mammal. 78, 999-1013.

Bueno, R.S., Guevara, R., Ribeiro, M.C., Culot, L., Bufalo, F.S., Galetti, M., 2013. Functional redundancy and complementarities of seed dispersal by the last Neotropical megafrugivores. PLoS One 8, 1-10.

Burnham, K.P., Anderson, D.R., 2002. Model Selection and Multimodel Inference, second ed. Springer, Berlin, Heidelberg, New York

Cassano, C.R., Kierulff, M.C.M., Chiarello, A.G., 2011. The cacao agroforests of the Brazilian Atlantic forest as habitat for the endangered maned sloth Bradypus torquatus. Mamm. Biol. 76, 243-250.

Castellón, T.D., Sieving, K.E., 2006. An experimental test of matrix permeability and corridor use by an endemic understory bird. Conserv. Biol. 20, 135-145.

Centoducatte, L.D., 2011. Fragmentação da Mata Atlântica e Conservação do muriqui-do-norte, Brachyteles hypoxanthus (Primates, Atelidae). Universidade Federal do Espírito Santo (M. Sc. dissertation).

Chiarello, A., Moraes-Barros, N., 2014. Bradypus torquatus. The IUCN Red List of Threatened Species. Version 2014.2, www.iucnredlist.org (19.06.2015).

Chiarello, A.G., Chivers, D.J., Bassi, C., Maciel, M.A.F., Moreira, L.S., Bazzalo, M., 2004. A translocation experiment for the conservation of maned sloths, Bradypus torquatus (Xenarthra, Bradypodidae). Biol. Conserv. 118, 421-430.

Chiarello, A.G., 1998a. Activity budgets and ranging patterns of the Atlantic forest maned sloth Bradypus torquatus (Xenarthra: bradypodidae). J. Zool. 246, 1-10.

Chiarello, A.G., 1998b. Diet of the Atlantic forest maned sloth Bradypus torquatus (Xenarthra: bradypodidae). J. Zool. 246, 11-19.

Chiarello, A.G., 2008. Sloth ecology: an overview of field studies. In: Vizcaíno, S.F., Loughry, W.J. (Eds.), The Biology of the Xenarthra. University Press of Florida, Gainesville, pp. 269-280.
Climate-data, 2015. Climate: Santa Maria De Jetibá, http://en.climate-data.org/ location/43571/ (31.01.2015).

Cooch, E.G., White, G.C., 2014. Program MARK-A Gentle Introduction. 13th ed

Dias, B.B., 2008. Área de vida e densidade populacional da preguiça-de-coleira Bradypus torquatus (Pilosa: Bradypodidae) na Mata Atlântica da região serrana do Espírito Santo. Pontifícia Universidade Católica de Minas Gerais (M. Sc. dissertation).

ESRI, 2013. ArcGis, the Complete Geographical Information System. Redlands, California. http://www.esri.com/ (10.10.2013).

Estes, G.M., Kuespert, D., 1976. Delphi in industrial forecasting. Chem. Eng. News, 40-47.

Fahrig, L., 2003. Effects of habitat fragmentation on biodiversity. Annu. Rev. Ecol. Evol. Syst. 34, 487-515.

Fortin, M.J., Dale, M.R.T., 2005. Spatial Analysis: A Guide for Ecologists. Cambridge University Press, Cambridge.

Gascon, C., Lovejoy, T.E., Bierregaard Jr, R.O., Malcolm, J.R., Stouffer, P.C., Vasconcelos, H.L., Laurance, W.F., Zimmerman, B., Tocher, M., Borges, S., 1999. Matrix habitat and species richness in tropical forest remnants. Biol. Conserv. 91, 223-229.

Gentile, R., Fernandez, F.a.S., 1999. Influence of habitat structure on a streamside small mammal community in a Brazilian rural area. Mammalia 63, 29-40.

Giné, G.A.F., Cassano, C.R., Almeida, S.S., Faria, D., 2015. Activity budget, pattern and rhythm of maned sloths (Bradypus torquatus): responses to variations in ambient temperature. Mamm. Biol. 80, 459-467.

Gouveia, S.F., Villalobos, F., Dobrovolski, R., Beltrão-Mendes, R., Ferrari, S.F., 2014 Forest structure drives global diversity of primates. J. Anim. Ecol. 83, $1523-1530$

Grelle, C.E.V., 2003. Forest structure and vertical stratification of small mammals in a secondary atlantic forest, Southeastern Brazil. Stud. Neotrop. Fauna Environ. $38,81-85$

Hines, J.E., 2006. PRESENCE-Software to Estimate Patch Occupancy and Related Parameters Version 7.8. USGS-PWRC, www.mbr-pwrc.usgs.gov/software/ presence.html (10.10.2013).

Hirsch, A., Chiarello, A.G., 2012. The endangered maned sloth Bradypus torquatus of the Brazilian Atlantic forest: a review and update of geographical distribution and habitat preferences. Mamm. Rev. 42, 35-54

Jose, S., 2009. Agroforestry for ecosystem services and environmental benefits: an overview. Agrofor. Syst. 76, 1-10.

Kajin, M., Grelle, C.E.V., 2012. Microhabitat selection when detection is imperfect: the case of an endemic Atlantic forest mammal. Ecol. Res. 27, 1005-1013.

Laurance, W.F., Peres, C.A., 2006. Emerging Threats to Tropical Forests. University of Chicago Press.

Laurance, W.F., Vasconcelos, H.L., 2009. Consequências ecológicas da fragmentação florestal na amazônia. Oecol. Bras. 13, 434-451.

Laurance, W.F., 2005. When bigger is better: the need for Amazonian mega-reserves. Trends Ecol. Evol. 20, 645-648.

Laurance, W., 2008. Theory meets reality: how habitat fragmentation research has transcended island biogeographic theory. Biol. Conserv. 41, 1731-1744.

Mackenzie, D.I., Nichols, J.D., Royle, J.A., Pollock, K.H., Bailey, L.L., Hines, J.E., 2006 Occupancy Estimation and Modeling-Inferring Patterns and Dynamics of Species Occurrence, first ed. Academic Press, Boston.

Martensen, A.C., Ribeiro, M.C., Banks-Leite, C., Prado, P.I., Metzger, J.P., 2012. Associations of forest cover fragment area, and connectivity with Neotropical understory bird species richness and abundance. Conserv. Biol. 26, 1100-1111.

Mayaux, P., Holmgren, P., Achard, F., Eva, H., Stibig, H., Branthomme, A., 2005. Tropical forest cover change in the 1990 and options for future monitoring. Philos. Trans. R. Soc. Lond. B. Biol. Sci. 360, 373-384.

Mendes, S. L., 2006. Viabilidade populacional do muriqui, Brachyteles hypoxanthus (Primates, Atelidae), em fragmentos de Mata Atlântica no Estado do Espírito Santo-Fase II. Relatório Final.

Metzger, J.P., Martensen, A.C., Dixo, M., Bernacci, L.C., Ribeiro, M.C., Teixeira, A.M.G., Pardini, R., 2009. Time-lag in biological responses to landscape changes in a highly dynamic Atlantic forest region. Biol. Conserv. 142, 1166-1177.

Moguel, P., Toledo, V.M., 1999. Biodiversity conservation in traditional coffee systems. Conserv. Biol. 13, 11-21.

Montgomery, G.G., Sunquist, M.E., 1975. Impact of sloths on Neotropical forest energy flow and nutrient cycling. In: Golley, F.B., Medina, E. (Eds.), Tropical Ecology Systems: Trends in Terrestrial and Aquatic Research. Springer-Verlog, Berlin, pp. 69-98.

Montgomery, G.G., 1978. Habitat selection and use by two and three-toed sloths. In: Montgomery, G.G. (Ed.), The Ecology of Arboreal Folivores. Smithsonian institution Press, Washington, pp. 329-359.

Mukherjee, N., Huge, J., Sutherland, W.J., McNeil, J., Opstal, M.V., Dahdouh-Guebas, F., Koedan, N., 2015. The Delphi technique in ecology and biological conservation: applications and guidelines. Methods Ecol. Evol. 6, 1097-1109.

Muylaert, R.L., Stevens, R.D., Ribeiro, M.C., 2016. Threshold effect of habitat loss on bat richness in Cerrado-forest landscapes. Ecol. Appl., 1-14.

Neteler, M., Mitasova, H., 2013. Open source GIS: a GRASS GIS approach. In: The International Series in Engineering and Computer Science, third edition. Springer, https://grass.osgeo.org/ (22.02.2014).

Olivo, M.A., Zickel, C.S., Almeida Jr., E.B., 2006. Flora e fitossociologia do estrato herbáceo de uma restinga no nordeste do Brasil. An. da 58 $\stackrel{a}{-}$ Reun. Anu. da SBPC, Santa Catarina.

Pütz, S., Groeneveld, J., Alves, L.F., Metzger, J.P., Huth, A., 2011. Fragmentation drives tropical forest fragments to early successional states: a modelling study for Brazilian Atlantic forests. Ecol. Modell. 222, 1986-1997. 
Peery, M.Z., Pauli, J.N., 2014. Shade-grown cacao supports a self-sustaining population of two-toed but not three-toed sloths. J. Appl. Ecol. 51, 162-170.

Prevedello, J.A., Vieira, M.V., 2010. Plantation rows as dispersal routes: a test with didelphid marsupials in the Atlantic Forest. Brazil. Biol. Conserv. 143, 131-135.

R Development Core Team, 2010. R: a Language and Environment for Statistical Computing (20.09.2014) www.r-project.org.

Ribeiro, M.C., Metzger, J.P., Martensen, A.C., Ponzoni, F.J., Hirota, M.M., 2009. The Brazilian Atlantic Forest: how much is left, and how is the remaining forest distributed? Implications for conservation. Biol. Conserv. 142, 1141-1153.

Richards, P.W., 1996. The Tropical Rain Forest: an Ecological Study. Cambridge University Press.

Ricketts, T.H., 2001. The matrix matters: effective isolation in fragmented landscapes. Am. Nat. 158, 87-99.

Ries, L., Debinski, D.M., 2001. Butterfly responses to habitat edges in the highly fragmented prairies of Central Iowa. J. Anim. Ecol. 70, 840-852.

Rodríguez, A., Andrén, J., Jansson, G., 2001. Habitat mediated predation risk and decision making of small birds at forest edges. Oikos 95, 383-396.

Sanquetta, C.R., Dalla Corte, A.P., Kovalek, N., 2011. Estrutura e composição de copas e clareiras em um fragmento de Floresta Ombrófila Mista no centro-sul do Estado Paraná. Rev. Estud. Ambient. 13, 68-77.

Santos, A.R., Júnior, H.C.A., Eugenio, F.C., 2012. Evolução da Cobertura Florestal no Município de Santa Maria de Jetibá -ES. Floresta e Ambiente 19, 296-307.
Silva, S.M., Summa, J.L., Summa, M.E.L., Geraldi, V.C., Belluci, M., Klefasz, A., Moraes-Barros, N., 2014. Contibution of wildlife governmental to conservation and biological study of sloths Bradypus variegatus. J. Nat. Conserv. 12, 79-85.

Silva, L.G. Ribeiro, M.C., Hasui, É da Costa, C.A da Cunha, R.G.T. 2015. Patch size, functional isolation, visibility and matrix permeability influences neotropical primate occurrence within highly fragmented landscapes. PLoS One 10, 1-20.

Tscharntke, T., Steffan-Dewenter, I., Kruess, A., Thies, C., 2002. Contribution of small habitat fragments to conservation of insect communities of grassland-cropland landscapes. Ecol. Appl. 12, 354-363.

Vaughan, C., Ramirez, O., Herrera, G., Guries, R., 2007. Spatial ecology and conservation of two sloth species in a cacao landscape in Limón, Costa Rica. Biodivers. Conserv. 16, 2293-2310.

White, G., Burnham, K.P., 1999. Program MARK: survival estimation from populations of marked animals. Bird Study 46, 120-138.

Zollner, P.A., Lima, S.L., 2005. Behavioral tradeoffs when dispersing across a patchy landscape. Oikos 108, 219-230.

Zuur, A.G., Ieno, E.N., Walker, N.J., Savaliev, A.A., Smith, G.M., 2009. Mixed Effects Models and Extensions in Ecology with R. Springer, New York, pp. 574 